\title{
The use of ultrasound as a research tool in acupunture: a literature review
}

\author{
Sánchez Lorenzo M. ${ }^{1} \quad$ Seoane Pardo R. ${ }^{1}$ \\ ${ }^{1}$ Tambre Fisioterapia, Sigüeiro, A Coruña, Spain \\ Rev Fisioter Invasiva 2019;2:82.
}

\begin{abstract}
Background and Aims Ultrasound is a non-invasive test which enables a fast real time exam, which is both dynamic and accessible. In contrast, the mechanisms of functioning of acupuncture have not been completely understood. The aim of this review was to determine the various uses assigned to ultrasound in acupuncture research.

Material and Methods A literature search was performed in PubMed, Cochrane Library, PEDro and ScienceDirect databases. Manual searches were performed in the following journals: Evidence-Based Complementary and Alternative Medicine, Acupuncture Medicine, Medical Acupuncture and The Journal of Alternative and Complementary Medicine. The search terms "ultrasonography" and "Acupuncture" were used, related with AND. Research studies in humans were included in which ultrasound was used to assess some aspect of the acupuncture intervention. No time limit was established and the languages were limited to Spanish, English, Galician or Portuguese. The data extraction was performed by two independently blinded evaluators.

Results A total of 46 studies were included for the analysis. B Mode is the most used form of imaging, followed by Doppler and elastography. In total, 18 studies performed an analysis of vascular parameters. Doppler was commonly used, with a dominance of transcranial Doppler methods, although B mode was also used to measure the transverse diameter of blood vessels. In 11 studies, B mode was used alone or combined with Doppler to obtain measures of safety, precision, location of target structures and needle position regarding sensitive structures. Seven studies used elastography. Five studies quantified tissue movement and another quantified muscle stiffness using elastography and B mode. A further study also included Doppler for the measurement of blood flow. Six studies evaluated visceral conditions. One study evaluated gastric emptying and the five remaining studies focused on the genitourinary sphere such as the rate of pregnancy, fetal position, prostate characteristics, intrapelvic venous congestion and bladder emptying. From the musculoskeletal point of view, 4 studies were located. Two studies evaluated the thickness parameter of the common extensor tendon of the epicondyle and two layers of connective tissue,

Keywords

- acupuncture

- ultrasonography

- review

- systematic

- research respectively. One study concluded that the application of acupuncture can influence the viscoelastic properties of the tendon and one remaining study informed of the positive association between ultrasound as an assessment tool and follow up tool in acupuncture treatments.

Conclusions In this field of study, ultrasound has been used to obtain objective outcomes and adopt safety guidelines related to acupuncture procedures.
\end{abstract}

DOI https://doi.org/ 10.1055/s-0039-3401864. ISSN 2386-4591.
Copyright $\odot 2019$ by Thieme Revinter

Publicações Ltda, Rio de Janeiro, Brazil
License terms

$\circledast(1) \Theta \circledast$ 